\title{
Transient cerebral ischaemic attacks related to egg consumption
}

\author{
M. E. Ellis \\ M.R.C.P.
}

\author{
DAVID L. STEVens \\ M.D., F.R.C.P.
}

\author{
Cheltenham General Hospital, Sandford Road, Cheltenham, Glos.
}

\begin{abstract}
Summary
A 58-year-old man is described who suffered transient cerebral ischaemic attacks when on a diet containing a large number of eggs. When the egg content and, therefore, the cholesterol content of the diet was reduced the attacks stopped. It was concluded that the variations in his cholesterol intake and in his serum cholesterol, which remained normal or near normal throughout, are relevant to the aetiology of his episodes of cerebral ischaemia and that further study of techniques designed to alter the cholesterol intake and the cholesterol level in patients with such attacks may be useful.
\end{abstract}

\section{Case report}

A 58-year-old man gave a 4-year history of recurrent and increasingly frequent attacks of transient left homonymous hemianopia, with occasional associated rotatory vertigo, occipital headache and partial amnesia. Each attack lasted for approximately $15 \mathrm{~min}$ and recovery was always complete. With the exception of intermittent claudication, he was otherwise well and, in particular, did not suffer from migraine or any allergic disorders. Before consulting the authors, he had observed that his attacks did not occur if he refrained from eating eggs.

An analysis of his diet revealed that his average daily energy intake was $18.5 \mathrm{~kJ}(4.4 \mathrm{kcal})$ and that he had a marked predeliction for cream cakes, fried foods and eggs. The diet was rich in carbohydrate, saturated fatty acids and cholesterol; indeed the average daily intake of the latter was $1035 \mathrm{mg}$, which is double the national average (Thompson, 1978). Eggs provided $65 \%$ of the cholesterol intake, for each week he consumed 17 cooked eggs as well as a further 5 in cakes and prepared foods.

Physical examination revealed a stable BP of $130 / 70 \mathrm{mmHg}$ in both arms, with no variation on change of posture; a regular pulse of $65 / \mathrm{min}$ and a normal heart. A soft right carotid bruit was audibfe The rest of the general examination was normal and no cutaneous or other stigmata of hyperlipidaemige were found. No abnormal neurological signs we discovered.

$X$-rays of the chest and cervical spine were normal, as were the full blood count, plasma vis cosity, blood sugar, fasting lipid profile and ECE. The VDRL and Treponema pallidum haemagglugnation assay (TPHA) tests yielded negative resylts. Aortic arch aortography demonstrated slight narof ing of the origin of the left vertebral artery, but no other abnormality. A skin-prick test to egg negative. With informed consent he was given variety of experimental diets with different egg and cholesterol contents. During the period of com sumption of these diets his cholesterol and lip protein levels were monitored and he kept a detailed diary of the frequency of his attacks. Throughog t this time he was not given any other form of treafment. Table 1 contains a summary of his progress. The study lasted 49 weeks and in this time he had 20 attacks, 19 of which occurred during the 22 weeks when he was consuming 22 eggs/week, whereas ond one attack occurred during the 27 weeks when h weekly egg consumption was 5 or less. These data strikingly confirm the observation that he had made himself before his original consultation. Other adjustments to his diet, such as modification of the total saturated fatty acid content had a less mark effect. Repeated measurements of the cholester and fasting lipoprotein profile (using the nephelö metric technique employed by the laboratory at that time) revealed modest changes which were by and large within the normal range.

Since the end of the experimental period he has been maintained on a low cholesterol ( $<300 \mathrm{mg} /$ da low saturated fat, high unsaturated fat diet. addition he has taken enteric-coated aspirin $600 \mathrm{mg}$ twice/day. On this regime he has been totally symptom-free for 2 years. 
TABLE 1. Changes in frequency of attack, serum cholesterol and lipoprotein values on various experimental diets

\begin{tabular}{|c|c|c|c|c|c|c|}
\hline Diet number & 1 & 2 & 3 & 4 & 5 & 6 \\
\hline $\begin{array}{l}\text { Diet: } \\
\text { Total egg intake/week }\end{array}$ & 22 & 5 & 5 & 22 & 0 & 22 \\
\hline $\begin{array}{l}\text { Gross saturated fatty } \\
\text { acid and cholesterol content } \\
\text { Cholesterol intake (mg/day) }\end{array}$ & $\begin{array}{l}\text { High } \\
1035\end{array}$ & $\begin{array}{l}\text { High } \\
520\end{array}$ & $\begin{array}{l}\text { Reduced } \\
385\end{array}$ & $\begin{array}{c}\text { Reduced } \\
940\end{array}$ & $\begin{array}{l}\text { Minimal } \\
<300\end{array}$ & $\begin{array}{l}\text { High } \\
1035\end{array}$ \\
\hline $\begin{array}{l}\text { Duration of diet (weeks) } \\
\text { No. of TIAs } \\
\text { Average TIAs/4-week period } \\
\text { Serum cholesterol (mmol/l) } \\
(\text { Normal }=3 \cdot 8-6 \cdot 5)\end{array}$ & $\begin{array}{c}12 \\
12 \\
4 \\
6 \cdot 8\end{array}$ & $\begin{array}{l}12 \\
0 \\
0 \\
5 \cdot 4\end{array}$ & $\begin{array}{l}12 \\
1 \\
0 \cdot 25 \\
5 \cdot 8\end{array}$ & $\begin{array}{l}6 \\
4 \\
2 \cdot 6 \\
6 \cdot 1\end{array}$ & $\begin{array}{l}3 \\
0 \\
0 \\
5 \cdot 1\end{array}$ & $\begin{array}{l}4 \\
3 \\
3 \\
6 \cdot 4\end{array}$ \\
\hline $\begin{array}{l}\text { Lipoproteins }(\mathrm{g} / \mathrm{l}) \text { (normal values) } \\
\text { small }(<5 \cdot 5) \\
\text { medium }(<2 \cdot 4) \\
\text { large }(<0 \cdot 28)\end{array}$ & $\begin{array}{l}5 \cdot 6 \\
2 \cdot 4 \\
0 \cdot 80\end{array}$ & $\begin{array}{l}4 \cdot 5 \\
1 \cdot 2 \\
0 \cdot 13\end{array}$ & $\begin{array}{l}4 \cdot 8 \\
0.95 \\
0 \cdot 15\end{array}$ & $\begin{array}{l}5 \cdot 0 \\
0.9 \\
0 \cdot 12\end{array}$ & $\begin{array}{l}4 \cdot 3 \\
0 \cdot 6 \\
0 \cdot 12\end{array}$ & $\begin{array}{l}- \\
- \\
-\end{array}$ \\
\hline
\end{tabular}

TIA $=$ transient ischaemic attack

\section{Discussion}

The patient described has neurological symptoms when he eats eggs. When he abstains from eggs the symptoms do not occur. This raises the question: how can egg consumption do this?

Kennedy (1926) discussed a condition known as 'cerebral food allergy', in which transient visual loss, focal neurological signs, headache, urticaria and other evidence of allergy followed consumption of certain foods. Patients with food allergies are generally young and their symptoms usually follow closely on the eating of the relevant allergen. They commonly have eosinophilia or rhinitis, and skin tests to the allergen may be positive, although it has to be acknowledged that such testing is often unreliable. The present patient is not in the right age group for such an allergy, he has no other evidence of an allergic diathesis and his symptoms have never followed closely upon the consumption of the putative allergen, which in this case is egg. On these grounds, the hypothesis that his symptoms may reflect a specific food allergy has been rejected.

Some patients with migraine claim that their attacks are precipitated by certain foodstuffs and eggs are sometimes implicated in this context. It is rare for such relationships to be clear-cut and attacks frequently continue to occur, despite avoidance of the responsible substance. It is assumed that the basis for dietary migraine is some ill understood allergic mechanism.

The attacks experienced by this patient, particularly those in which headache occurred, could be regarded as migrainous. However, the onset at a late age, the evidence of vascular disease elsewhere and the rather variable nature of the symptoms, make this an unattractive diagnosis. The virtual cessation of attacks when on a low-egg diet would be unusual if the cause were migraine. For these reasons, the hypothesis that his symptoms may be migrainous has also been rejected.

The most likely explanation for the attacks is that they are transient ischaemic episodes within the territories of the basilar and posterior cerebral arteries. Supporting evidence for this view comes from the demonstration of a narrow origin of one vertebral artery, the presence of a carotid bruit and a story of intermittent claudication.

The question that remains concerns the mechanism of production of the attacks. It appears reasonable to attempt to implicate cholesterol, for it has been observed that the attacks occur when the patient is on a high egg and, therefore, a high cholesterol diet and that they more or less cease when the cholesterol intake is low. The most interesting observation in this context is that his serum cholesterol was normal or near normal throughout and that the variations in the concentration, which correspond well with the dietary intake, are within the normal range. The authors have demonstrated that his attacks are more frequent when the cholesterol and lipoprotein values are somewhat high and that they do not occur when the concentrations are low.

The role of cholesterol in the aetiology of stroke and of transient cerebral ischaemic attacks has been reviewed by Hutchinson and Acheson (1975) and they conclude that 'elevation of serum cholesterol does not appear to bear the same close relationship to disease of the cerebral vasculature as it does in the case of coronary artery disease'. Data from the Framingham study and others are beginning to point towards an independent role for cholesterol as a contributory factor in the genesis of stroke (Ross-Russell, 1976) but the case for such a role is far from established. Such evidence is based, by and large, upon the observation of elevated cholesterol concentrations in individuals with stroke or in those 
who subsequently develop stroke. Thus, the role of high normal, or fluctuating but still normal, cholesterol concentrations has not been studied with the same enthusiasm as the frankly elevated cholesterol concentration in such patients.

These observations appear important in this context, for the authors have demonstrated that a high intake, and therefore a high turnover, of cholesterol in a patient who has an essentially normal concentration of cholesterol in his serum, is highly relevant in the aetiology of his transient ischaemic attacks. It is possible that the deleterious effect of the cholesterol and the associated fatty acids, such as linoleic acid, is mediated through the prostacyclin mechanisms that influence platelet stickiness, with consequent alteration in platelet behaviour and the production of microemboli. Presumably the reduction in cholesterol intake led to a reduced cholesterol turnover as well as a modest reduction in cholesterol blood level and that this permitted platelet function and behaviour to alter with a resultant fall in attack frequency. Theoretically, the altered diet may have been all that was required, but it was felt that additional confiden would be obtained from the use of an 'anti-platelet stickiness' agent, which is why aspirin was added 19 his treatment regime at the end of the experimentil period.

It can be concluded that in the present patie cholesterol appears to have a significant role in the aetiology of his transient ischaemic attacks and the authors' observations lead them to suggest that future study of techniques designed to manipulate cholesterol intake and homoeostasis may be more fruitful than has hitherto been apparent.

\section{References}

Hutchinson, E.C. \& ACHESON, E.J. (1975) Strokes: Natuxal History, Pathology and Surgical Treatment. W. Saunders, London.

KeNNEDY, F. (1926) Cerebral symptoms induced angioneurotic edema. Archives of Neurology and Ps,
cology, Chicago, 15, 28.

Ross-Russell, R.W. (1976) Cerebral Arterial Diseas. Churchill-Livingstone, London.

Thompson, G. (1978) Plasma lipoproteins and their disorders. Medicine (3rd series), 11, 559. 